\section{Danger: men at work}

\author{
Judy Redfearn looks at the problems facing \\ those concerned with major hazards in Britain
}

LMOST three years ago an explo-
sion at a Nypro factory in Flix-
borough killed 28 people and injured
more than 100 . It shocked the British
public into awareness of the possibility
of other major industrial acidents.
The Health and Safety Commission's
Advisory Committee on Major Hazards
was set up in the wake of Flixborough
to lay down recommendations for the
control and supervision of major
hazards. Nine months ago it published
its first report, which helped those con-
cerned with industrial safety to think
seriously about its recommendations
and how to implement them. Some of
the problems that report brought to
light have since been discussed, notably
at a meeting organised by the Institu-
tion of Mechanical Engineers at the
beginning of May, when representa-
tives from industry, local authorities,
the Health and Safety Executive (HSE)
and the committee itself got together
in London.

The report's main recommendation poses a major problem. The recommendation was that a 'notification' scheme should be set up to help the HSE compile a list of major hazards: all installations would be subject to review, even though most would demand no more regulation than already exists under the 1974 Health and Safety at Work Act; but potentially hazardous installations would be required to submit a detailed survey of their activities to the HSE. At the moment, this is voluntary, but the committee would like to see it enforced by legislation.

The problem with the scheme is the burden it will impose on the HSE. Not only will the Executive receive a large number of surveys from all kinds of installations; it will also need to examine in great depth those which might indicate a major hazard. To relieve some of this burden, the committee has suggested that individual companies should be responsible for indicating their own problems and outlining the solutions. But this still means the HSE will need more specialised staff. The committee has suggested that outside expertise should be made available at any time.

Another difficulty is that it is not yet clear how the top league of hazardous installations would be controlled: whether by regulation or licensing. The committee feels that it can only wait until both local authorities and the HSE have acquired, under the notification scheme, fairly comprehensive in- formation on the types of activity they will be controlling and on the problems they will be facing before it can recommend which way to go. One of the dangers it wishes to avoid is transferring liability for major accidents from industry to the regulating body. Whatever machinery is set up, some industrialists feel that a major stumbling block will come in trying to ensure that their special case is understood by whoever is to judge it. And in the end what does or does not constitute a major hazard will be someone's subjective judgment.

Nor is this all. Accidents happen-either through the fault of people operating machinery or through mechanical breakdown-but the extent of the damage they cause depends on environmental factors. The report recommended that new plants should be planned to take account of the likely consequences of a major accident: buildings should be capable of withstanding shock from explosions and of containing toxic chemical leaks and should be situated away from densely populated areas. Machinery should be designed to the highest specifications and staff should be continually retrained in operating procedures.

The trouble is, human error can never be eliminated, whether in the design or in the operation of an industrial plant. The recent meeting produced a general call for more research into the relative safety of automatic control systems and human control: it was asked, for example, whether it was safer to leave everything to machines and to have no one about when an accident does happen, or to have somebody there to warn others when something goes wrong. The committee is also concerned about the lack of knowledge on the massive release of toxic and flammable gases that are heavier or lighter than air.

Industry expects other problems once a plant has been labelled a 'notifiable installation'. For example, people have to be convinced that it is safe to work there. The feeling is that if a reputation has been established for giving reliable information on all aspects of its work, employees are likely to trust what is said about safety. The difficulty is that too often in the past industries have been found to have wrong statistics even on fundamental points. Public confidence will only be inspired if industries are seen to be reliable. A possible way of educating the public might be through the unions, but they have yet to be approached.

The committee's work is still in its first stages. It plans to hear more evidence and produce other reports as and when it sees fit. It still has many points to clarify before it can recommend further action and through the HSE it is liaising with the Dutch-the only other nation looking into major hazards. In the meantime it is simply waiting to see what turns up. 